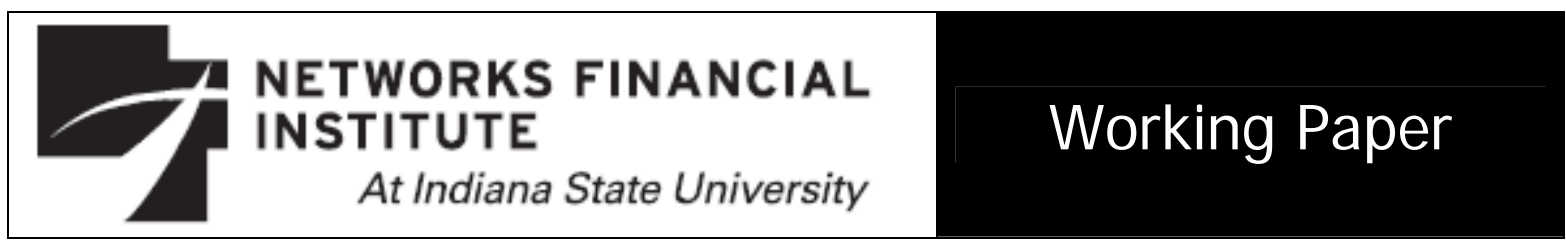

2007-WP-12

April 2007

\title{
No Pain, No Strain: I mpact of Health on the Financial Security of Older Americans
}

\section{Angela Lyons and Hyungsoo Kim}

\begin{abstract}
This study uses data from the 2002 and 2004 Health and Retirement Study to investigate the impact that health problems have on the financial strain of older Americans. Two-stage probit models are estimated for a series of financial ratio guidelines that take into account household solvency, liquidity, and investment asset accumulation. We test our models using a subjective measure of self-reported health status and two objective measures of health that control for the severity of specific health conditions. The results show that health problems significantly increase the likelihood of financial strain for older individuals, and the magnitudes of the effects vary by the type of financial strain and how health status is defined. Those most likely to experience some type of financial strain are those with severe chronic conditions. The results provide insight into the future financial security of older Americans and have important implications for health policy and research.
\end{abstract}

\section{About the Authors:}

Angela Lyons is an Assistant Professor at University of Illinois at Urbana-Champaign.

Hyungsoo Kim is an Assistant Professor at University of Kentucky.

The views expressed are those of the individual author and do not necessarily reflect official positions of Networks Financial Institute. Please address questions regarding content to Angela Lyons at anglyons@illinois.edu. Any errors or omissions are the responsibility of the author.

NFI working papers and other publications are available on NFI's website (www.networksfinancialinstitute.org). Click "Research" and then "Publications/Papers." 


\section{No Pain, No Strain: \\ Impact of Health on the Financial Security of Older Americans*}

\section{Angela Lyons and Hyungsoo Kim}

As the U.S. population ages, there is considerable debate about whether rising health care costs and growing levels of household debt threaten the future financial security of older Americans (Copeland 2006; Johnson and Penner 2004). Currently, research shows that individuals aged 65 or older spend, on average, 19 percent of their income on out-of-pocket health care expenditures, including health insurance premiums (Crystal et al. 2000). However, out-of-pocket health care expenditures are projected to increase to at least 30 percent of after-tax income for older families by 2030 (Johnson and Penner 2004).

In addition to concerns over rising health care costs, there is growing concern that older Americans are accumulating too much debt. In recent years, the average total debt held by a family with a head aged 55 or older rose significantly, from $\$ 29,309$ in 1992 to $\$ 51,791$ in 2004 (Copeland 2006). ${ }^{1}$ The average debt held by a family head aged 75 or older increased by even more, from $\$ 7,769$ in 1992 to $\$ 20,234$ in 2004, an increase of over 160 percent. Debt levels grew fastest for lower-income families. Specifically, families in the lowest income quartiles experienced the largest percentage point increases in debt, from 38.0 percent in 2001 to 47.0 percent in 2004. If current projections are accurate, health care costs and household debt levels will continue to rise, resulting in greater financial strain for older Americans (Copeland 2006; Johnson and Penner 2004).

\footnotetext{
* This paper was awarded the AARP's Public Policy Institute Paper Award at the 2007 Conference of the American Council on Consumer Interests. We graciously thank AARP for their recognition and support of this research.

${ }^{1}$ All amounts were adjusted for inflation and are in 2004 dollars.
} 
Previous research has examined how health affects the wealth depletion of the elderly (Hurd and Kapteyn 2003; Kim and Lee 2005; Lee and Kim 2003; Smith 1999, 2003). These studies have found that poor health significantly increases wealth depletion. This research, however, does not adequately investigate the extent to which health affects the overall financial security of older Americans. To what extent does wealth depletion result in serious financial strain such as insolvency? Also, as wealth is depleted, how do the financial portfolios of older individuals change in response to health problems? Many older Americans, especially those who are retired, do not have earnings they can use to cover unexpected health care costs. Unlike the working population, they have to spend larger portions of their income on health care expenses as well as larger shares of their retirement wealth. For this reason, older Americans with health problems may experience changes in their portfolios, such as those related to liquidity and investment asset holdings.

Our study builds upon previous research and uses longitudinal analysis to provide a more complete picture of the effect that health status has on the financial strain of older Americans. Using data from the 2002 and 2004 Health and Retirement Study, we construct a series of financial ratio guidelines that account for a household's degree of financial strain (e.g., solvency, liquidity, and investment asset accumulation). We then estimate a series of two-stage probit models for a sample of the U.S. population aged 65 or older to examine the impact that new and existing health events have on current financial strain and changes in financial strain. We test our models using both a subjective measure of self-reported health status and two objective measures of health that control for the severity of specific health conditions. The results of this study provide insight into the future financial security of older Americans and have important implications for health policy and research. 


\section{LITERATURE REVIEW}

\section{Health and Socioeconomic Status}

A large body of research has examined the relationship between health and socioeconomic status (SES). Some studies have focused primarily on the impact that SES has on health status, examining whether low SES (i.e., income and wealth) leads to poor health (i.e., Drentea and Lavrakas 2000; Jacoby 2002; Meer et al. 2003). These studies provide some evidence that lower SES can lead to poor health, either by the physical stress that financial strain creates or because of limited access to quality health care services. However, the effect of SES on health status is typically found to be very small.

The majority of research related to health and SES tends to show that poor health results in lower SES (i.e., Adams et al. 2003; Kim and Lee 2005; Lee and Kim 2003; Lyons and Yilmazer 2005; Michaud and van Soest 2004; Smith 1999, 2003; Wu 2003). In fact, it is welldocumented in the literature that the dominant direction of causation for older Americans is not

from SES to health, but from health to SES (Adams et al. 2003; Lee and Kim 2003; Michaud and van Soest 2004; Smith 1997, 1999).

The relationship between health and SES has been frequently documented using wealth, because wealth captures command over economic resources, particularly consumption opportunities (Hurd 1990; Smith 1997). The link from health to wealth has been found using a variety of wealth measures. Some studies have used total wealth and found that poor health decreases the dollar amount of wealth held by the individual (Adams et al. 2003; Smith 1999, 2003; $\mathrm{Wu} 2003)$. Other studies have used the percentage change in wealth between two time periods (Haider et al. 2000; Hurd and Kapteyn 2003). They found that unanticipated health expenses resulted in a 10 percent decrease in savings. Kim and Lee (2005) and Lee and Kim 
(2003) used a binary measure to identify individuals who had experienced a depletion in wealth that was greater than 10 or 30 percent. They found that those with health problems experienced a more accelerated decline in wealth depletion than those without health problems.

Overall, these studies have showed that health problems lead to declines in wealth for older Americans. However, this research has not adequately investigated the extent to which wealth depletion results in financial strain. In particular, do health problems deplete wealth to the point of insolvency? And, in turn, how do health problems affect the asset allocation of older individuals?

\section{Financial Ratios and Portfolio Allocation}

Researchers have identified several financial ratio guidelines that have been used to predict household financial strain such as liquidity problems and insolvency (i.e., Baek and DeVaney 2004; Chang et al. 1997; DeVaney 1994; DeVaney and Lytton 1995; Garman and Forgue 2006; Lyons and Yilmazer 2005; Yao, Hanna, and Montalto 2003; Zeldes 1989). These financial ratio guidelines focus on assessing a household's ability to avoid excessive debt (solvency ratio), maintain adequate liquidity (liquidity ratio), and make progress toward financial goals (investment assets ratio). Since each financial ratio captures a slightly different aspect of the financial position of the household, a single ratio may not be comprehensive enough to accurately capture the degree to which households are under financial strain (Baek and DeVaney 2004; Lyons and Yilmazer 2005). For this reason, one might want to take into consideration several of these financial guidelines when examining the financial strain of older Americans.

To date, little research has examined the link between these financial ratios and health status. Using cross-sectional data from the Survey of Consumer Finances (SCF), Lyons and Yilmazer (2005) used three financial guidelines (delinquent on loan payments; total assets/total 
debts less than 1.0; and liquid assets/income less than 0.25 ) to examine the relationship between self-reported health status and financial strain for a general sample of the U.S. population. They found that, for all three measures, poor health significantly increased the likelihood of financial strain. There was little evidence to show that financial strain contributed to poor health.

Two other recent studies by Rosen and Wu (2004) and Berkowitz and Qiu (2006) used data from the Health and Retirement Study (HRS) to examine how health status affects the portfolio allocation decisions of older Americans. Rosen and $\mathrm{Wu}$ (2004) found that health status was a significant predictor of both the probability of owning different types of financial assets and the proportion of total financial wealth allocated to each type of asset. Specifically, they found that older households in poor health were less likely to hold risky financial assets and more likely to hold a greater share of their financial wealth in safe assets. Berkowitz and Qiu (2006) looked at how changes in health status affected the financial asset and non-financial asset holdings of older Americans. They found that new health events led to larger declines in financial than non-financial wealth. The reduction in financial wealth further resulted in older households restructuring the composition of their financial assets.

\section{Heath Status Measures}

Within the literature, health status has been defined using a variety of measures. Despite differences in the measures used, little attention has been paid to investigating the impact that both self-reported and objective measures of health have on financial strain. Some studies have used individuals' self-reported subjective perceptions of their health. Self-reported measures serve as general indicators of health; typically, individuals are asked to rate their current health status from excellent to poor. While some have questioned the reliability and validity of selfreported measures, most research has found that they provide meaningful and reliable measures 
of an individual's actual health status (i.e., Baker, Stabile, and Deri 2001; Hoeymans, Feskens, Kromhout, and Van Den Bos 1997; Idler and Benyamini 1997; Idler and Kasl 1991, 1995; Meer, Miller, and Rosen 2003). Hurd and Kapteyn (2003) used self-reported measures from both U.S. data and data from the Netherlands to show that there was a strong positive association between health and income and health and wealth. Another recent study by Lyons and Yilmazer (2005) used a self-reported measure from the SCF to show that poor health positively, and significantly, affected financial strain.

Other studies have used more objective measures that control for the prevalence and incidence of specific health conditions such as functional impairments, medically-diagnosed conditions, and chronic diseases (Adams et al. 2003; Haider et al. 2000; Kim and Lee 2005; Lee and Kim 2003; Smith 1999, 2003; Wu 2003). These studies have examined how existing health conditions and new health events affect wealth depletion. Some also have looked at how these effects differ by the severity of the condition (i.e., a mild or severe chronic condition). In general, the findings show that severe chronic conditions have a significant impact on the wealth depletion of older Americans, while mild chronic conditions do not. The results further show that both new health events and existing chronic conditions lead to significant wealth depletion.

\section{METHODS}

\section{Theoretical Framework}

The life-cycle theory of consumption and savings provides a framework for explaining how older individuals spend down their financial resources as health problems arise and how the depletion of these resources can result in financial strain. In general, the life-cycle model describes how individuals save before retirement and dissave after retirement in order to finance consumption over the remainder of their lives (Modigliani and Brumberg 1954). The simplest 
model assumes that individuals exhaust all of their savings by the time of their death. Variations of the model further assume that individuals set aside some savings for the purpose of leaving a bequest. Individuals may also anticipate expenses for emergencies or long-term medical care and therefore, as a precautionary measure, set aside additional savings. Regardless, the fundamental prediction of the theory is that savings declines with age, implying that decreases in savings are planned or expected. This simple framework does not, however, take into consideration unexpected events or uncertainties that arise during the remainder of the individual's lifetime.

An individual's actual changes in savings may differ from planned changes due to unexpected events that positively or negatively affect overall savings. On the one hand, unanticipated financial events such as receiving unexpected gifts or inheritances can increase savings. On the other hand, other unexpected events, such as those stemming from health problems or a change in marital status, can accelerate planned declines in savings and result in older individuals running out of savings earlier than expected (Haider et al. 2000; Kim and Lee 2005; Lee and Kim 2003; Smith 1999). In such cases, savings may be depleted fairly quickly, placing financial strain on individuals, which in turn can threaten their overall financial security. This accelerated depletion of savings can lead to serious financial strain such as insolvency. A health problem can lead to an accelerated decline in savings via a number of channels. First, health problems, especially new health events and chronic conditions, can result in large and unexpected increases in health care expenditures (Haider et al. 2000; Lee and Kim 2003; Smith 1999, 2003). Individuals can transfer this health risk in later years by obtaining supplemental health insurance plans from former employers or by purchasing Medigap programs to supplement Medicare. These health insurance plans can help to mitigate declines in savings 
that result from unexpected health care expenditures and rising health care costs (Kim and Lee 2005; Smith 1999, 2003).

Second, health problems can increase non-medical consumption (Lillard and Weiss 1997). For example, when individuals have health problems, they may prefer to use transportation services instead of driving on their own. They also may cut back on household production such as cooking or cleaning and rely more on market goods and services. In addition, they may need to make modifications to their home to accommodate illness or disability (Kutty 1999). If older individuals have adult children, they may be able to mitigate the financial burden associated with a health condition by living with their children or having some other alternative living arrangement.

Third, health problems can lead to depletions in savings by reducing an individual's ability to work, resulting in reductions in current and future earnings. Most individuals over the age of 65 are retired, so the reduction of savings through earnings is not as relevant for this group. However, health problems can have a significant impact on wealth that was accumulated from previous earnings as well as other resources. Smith (1999) found that the onset of a new severe health condition resulted in about $\$ 17,000$ (or 7 percent) of wealth depletion for Americans aged 51-61. Also, Haider et al. (2000) found that unanticipated health expenses led to a 10 percent dissaving for Americans aged 70 or older.

Finally, health problems can affect savings by changing individuals' inter vivo and bequest behaviors (Hurd 1990; Smith 1999). Older individuals, who have health problems, may decrease or eliminate inter vivo transfers or inheritances to children in order to cover increases in health care expenditures. These reductions in transfers and bequests can help to slow decreases 
in savings that result from health problems. However, declines in savings are still likely to occur, especially for those with serious health conditions who have limited financial resources.

Overall, this theoretical framework provides some explanation for why older individuals who have an existing health problem or who experience an unexpected health event may be more likely to dissave and become financially strained (i.e., insolvent, illiquid, and asset depleted). It also provides context for our longitudinal analysis, which looks at how changes in health status affect financial strain across two time periods.

\section{Empirical Model}

In the simplest model, the relationship between health problems $\left(H_{i t}\right)$ and financial strain $\left(F S_{i t}\right)$ can be expressed as follows:

$$
\mathrm{FS}_{\mathrm{it}}{ }^{*}=\alpha+\beta \mathrm{H}_{\mathrm{it}}{ }^{*}+\gamma^{\prime} \mathrm{X}_{\mathrm{it}}+\varepsilon_{\mathrm{it}} .
$$

$F S_{i t}{ }^{*}$ and $H_{i t}{ }^{*}$ are continuous, latent random variables that represent the degree to which the $i^{\text {th }}$ individual in time period $t$ is financially strained and in poor health, respectively. While this type of cross-sectional model provides insight into the general relationship between health and financial strain, it makes it difficult to assess the direction of causation.

Recall, however, that the pathway from health to financial strain for older Americans has been well-documented in the literature, while the pathway from financial strain to health status has been found to be negligible. Thus, we focus on the impact that changes in health status have on the financial strain of older Americans and use longitudinal analysis to estimate the following two-stage probit model:

$$
\mathrm{FS}_{\mathrm{t}}=\alpha_{0}+\alpha_{1} \mathrm{H}_{\mathrm{t}-1}+\alpha_{2} \Delta \mathrm{H}_{\mathrm{t}-1, \mathrm{t}}+\alpha_{3} \mathrm{FS}_{\mathrm{t}-1}+\alpha_{4} \mathrm{X}_{\mathrm{t}-1, \mathrm{t}}+\varepsilon_{\mathrm{t}}
$$


According to this model, current financial strain $\left(F S_{t}\right)$ is determined dynamically by health in the previous period $\left(H_{t-1}\right)$, new health events that arise between the previous and current periods $\left(\Delta H_{t-1, t}\right)$, and financial strain in the previous period $\left(F S_{t-1}\right) . F S_{t}$ is the discrete dependent variable that is equal to one if the respondent reports being financially strained in the current period and zero otherwise. $F S_{t-1}, H_{t-1}$ and $\Delta H_{t-1, t}$ are also discrete choice variables. $F S_{t-1}$ is equal to one if the respondent reports being financially strained in the previous period, and $H_{t-1}$ is equal to one if the respondent reports being in fair or poor health in the previous period. $\Delta H_{t-1, t}$ represents a change in health status and is equal to one if the respondent reports that their health status worsened between $t-1$ and $t$.

$F S_{t}$ is also determined by a vector of exogenous factors, $X_{t-1, t}$. Included in $X_{t-1, t}$ are the financial characteristics of the household such as income, assets, monetary transfers, and previous levels of financial strain. $X_{t-1, t}$ also includes demographic factors that control for a respondent's age, gender, race/ethnicity, education, marital status, living arrangements, employment status, and how well the individual is covered by health insurance.

The key parameters of interest in our model are $\alpha_{1}$ and $\alpha_{2}$, which measure the impact that existing health conditions and new health events have on financial strain, respectively. In estimating equation (2), we assume that new health events that occur between $t-1$ and $t$ $\left(\Delta H_{t-1, t}\right)$ are exogenous sources of variations in health since they are likely to be unexpected when they initially occur. However, a health condition that occurred in $t-1$ is assumed to be an existing health condition that is expected and thus endogenous. For this reason, we use instrumental variable technique and estimate our model using a two-stage approach.

In the first stage, we obtain predicted values for $H_{t-1}$ using the probit method to estimate the following equation: 


$$
\mathrm{H}_{\mathrm{t}-1}=\pi_{1} \mathrm{~S}_{\mathrm{t}-1}+\pi_{2} \mathrm{E}_{\mathrm{t}-1}+\pi_{3}{ }^{\prime} \mathrm{X}_{\mathrm{t}-1}+\mathrm{u}_{\mathrm{t}-1} .
$$

In this model, we create an instrument for $H_{t-1}$ using two variables - smoking $\left(S_{t-1}\right)$ and exercise $\left(E_{t-1}\right)$. These variables were selected based on the availability of data and are consistent with those used in previous studies (Lee and Kim 2003; Lyons and Yilmazer 2005; Smith 1999). As Lyons and Yilmazer (2005) argue, health behaviors such as smoking and exercise are likely to directly affect health but unlikely to affect financial strain, except to the extent that these factors indirectly affect wealth and wealth affects financial strain. ${ }^{2}$ As a test, we included smoking and exercise in the financial strain equation and found that the instrumental variables did not have significant predictive power. ${ }^{3}$

The predicted values, $\hat{H}_{t-1}\left(=\hat{\pi}_{1} S_{t-1}+\hat{\pi}_{2} E_{t-1}+\hat{\pi}_{3}^{\prime} X_{t-1}\right)$, generated from Equation (3) are substituted into the right-hand side of Equation (2) such that:

$$
\mathrm{FS}_{\mathrm{t}}=\alpha_{0}+\alpha_{1} \hat{\mathrm{H}}_{\mathrm{t}-1}+\alpha_{2} \Delta \mathrm{H}_{\mathrm{t}-1, \mathrm{t}}+\alpha_{3} \mathrm{FS}_{\mathrm{t}-1}+\alpha_{4} \mathrm{X}_{\mathrm{t}-1, \mathrm{t}}+\varepsilon_{\mathrm{t}}
$$

In the second stage, the probit method is used again to estimate Equation (4) and obtain unbiased estimates of $\alpha_{1}$ and $\alpha_{2}$.

As a second longitudinal approach, we regress new health events $\left(\Delta H_{t-1, t}\right)$ that arise between the previous and current periods on changes in financial strain between the two periods $\left(\Delta F S_{t-1, t}\right)$. That is,

\footnotetext{
${ }^{2}$ There is additional evidence that smoking and other risky behaviors may be proxies for an individual's time preference such that individuals with low rates of time preference are more likely to engage in activities that increase human capital and future earnings as well as improve future health (i.e., Barsky et al. 1997). The HRS asks respondents about their planning horizon, which can be used to control for time preference. However, this information is only collected for individuals who are less than age 65 , primarily because those over 65 are at the end of the planning process. For this reason, we are unable to include this information in our model.

${ }^{3} \mathrm{We}$ also tested the validity of the instrumental variables using the following two conditions: (1) $\operatorname{corr}\left(S_{t-1} \operatorname{or} E_{t-1}\right.$, $\left.H_{t-1}\right) \neq 0$ and $\operatorname{corr}\left(S_{t-1}\right.$ or $\left.E_{t-1}, u_{t-1}\right)=0$. The findings from the validity tests are presented in the results section.
} 


$$
\Delta \mathrm{FS} \mathrm{t}-1, \mathrm{t}=\beta_{0}+\beta_{1} \mathrm{H}_{\mathrm{t}-1}+\beta_{2} \Delta \mathrm{H}_{\mathrm{t}-1, \mathrm{t}}+\beta_{3} \mathrm{X}_{\mathrm{t}-1, \mathrm{t}}+\varepsilon_{\mathrm{t}} .
$$

To estimate this model, we again use a two-stage probit model and instrumental variables to account for the possible endogeneity of $H_{t-1}$.

\section{DATA}

To estimate our models, we use data from the Health and Retirement Study (HRS), which is a national longitudinal study of older Americans sponsored by the National Institute on Aging (NIA). The HRS provides in-depth information on the financial position of households including income, assets and debts, which allows us to construct a series of financial ratio guidelines. The data also provide comprehensive information on the health status of individuals, including both subjective and objective measures of health such as self-reported health status and whether the individual has a specific health condition.

For our analysis, we use the most recent data from the 2002 and 2004 HRS. The 2002 HRS interviewed a nationally-representative probability sample of 18,167 respondents who were born prior to 1948. In order to look at how changes in health affect the financial strain of older Americans, we restrict our sample to include respondents who were aged 65 years or older in $2002(10,867$ respondents out of 18,167$)$ and who participated in both the 2002 and 2004 waves of the survey $(9,394$ respondents out of 10,867).

It is important to note that we conduct our analysis at the individual level. The HRS collects individual-level data on some factors such as health status; however, it also collects household-level data on other factors such as financial resources. If a couple is married in the HRS, both the husband and wife may be included as respondents regardless of whether both spouses were born in 1948 or earlier. In these cases, we calculate financial ratios at the 
household level and then assign the same ratio to the husband and wife if they are both included in the data set.

Because our analysis is conducted at the individual level, we use the respondent-level weights to yield unbiased estimates of the population parameters. The value of these probability weights is determined by the marital status of the respondent and the number of age-eligible persons in the household (Heeringa and Connor (1995), pp. 37-38). Thus, the weights adjust for the fact that both the husband and wife may be included as respondents in the data. For the purposes of this study, all of our data have been weighted.

Also note that the HRS sample is clustered and stratified, and unless this is taken into account, standard errors based on simple random sampling will tend to be biased downward. For our analysis, standard errors have been adjusted for sample clustering and stratification. ${ }^{4}$

\section{Financial Strain Measures}

We construct our dependent variables using three financial ratio guidelines, which serve as measures of financial strain for older Americans: a solvency ratio (total assets/total debts less than 1.0), a liquidity ratio (liquid assets/monthly income less than 2.5), and an investment assets ratio (investment assets/net worth less than 0.25$).{ }^{5}$ A dummy variable is created and set equal to one if the respondent reported that they were financially strained according to that particular ratio. Note that each ratio captures a slightly different aspect of financial strain.

The solvency ratio (total assets/total debts less than 1.0) identifies older respondents who are highly leveraged and close to being insolvent. These households are facing a wide range of financial challenges since their liabilities exceed their assets and they have retired or are close to

\footnotetext{
${ }^{4}$ For a complete overview of the HRS, visit: hrsonline.isr.umich.edu/docs/dmgt/IntroUserGuide.pdf. For a technical description of the sampling design, how the weights were created, and common methods used to compute standard errors, refer to Heeringa and Connor (1995).

${ }^{5}$ Note that, in order to calculate each ratio, a value of one was added to any amount in the denominator that was equal to zero.
} 
retiring. Thus, these individuals not only lack enough assets to cover their debts, but they may not have a current income flow that is flexible and sufficient enough to pay current bills and expenses. We define total assets as the sum of financial assets (checking accounts, savings accounts, money market funds, certificates of deposit, mutual funds, stocks, bonds, individual retirement accounts) and non-financial assets (primary residence and other real estate). Total debts are all debts including mortgage debt. This ratio is perhaps the most unambiguous measure of financial strain since by definition it defines insolvency.

The liquidity ratio (liquid assets/monthly income less than 2.5) captures the extent to which older Americans have sufficient liquid assets to cover about 2.5 months of income. Liquid assets include checking accounts, savings accounts, and money market funds. ${ }^{6}$ In general, financial planners recommend that individuals set aside an emergency fund with liquid savings worth about three-to-six months of living expenses (i.e., DeVaney 2004; Garman and Forgue 2006). Having an emergency fund insures that individuals, especially the elderly, are adequately prepared for unexpected expenses such as those related to a negative health shock. The 2.5 month cutoff may seem arbitrary. However, having an emergency fund that is slightly smaller than that recommended by the financial experts is likely to be more appropriate for older Americans since they have larger amounts of accumulated wealth than younger individuals. ${ }^{7}$ Keep in mind though that older individuals, who rely almost solely on limited incomes and who have not adequately prepared for retirement, may need a larger "cushion" to protect themselves

\footnotetext{
${ }^{6}$ The HRS asks respondents: "If you added up all such accounts (any checking or savings accounts or money market funds), about how much would they amount to right now?" This question is used to define liquid assets. The HRS also asks respondents to report the amount of assets they have in certificates of deposit, government savings bonds, and treasury bills. These amounts are reported in total and cannot be separated by type of asset. We estimated our models using this alternative definition of liquid assets (e.g., summation of checking or savings accounts, money market funds, CDs, government savings bonds, and treasury bills). The results were also robust to this definition of liquid assets.

${ }^{7}$ We examined a number of other cutoffs that were slightly larger and smaller than 2.5 months. The results did not change significantly.
} 
against unexpected health events. While the majority of older Americans have Medicare (98 percent), it only covers about half of all medical expenses (Ezzati-Rice, Kashihara, and Machlin 2004; Hurd and McGarry 1997). Also, a new health condition may be more likely than an existing one to have an impact on liquidity and a larger emergency fund may help to better mitigate the financial burdens associated with a new health event. ${ }^{8}$

Finally, the investment assets ratio (investment assets/net worth less than 0.25 ) identifies older individuals who have less than 25 percent of their net worth in investment assets. According to Baek and DeVaney (2004), individuals in the earlier stages of the life-cycle often have an investment assets ratio of less than 20 percent. However, as individuals advance through the life cycle, it is recommended that they maintain an investment assets ratio of at least 25 percent (DeVaney 2000; Lytton et al. 1991). This includes those who are 65 years or older. The investment assets ratio is a good indicator of how well older individuals have met their retirement savings goals. It also provides a good indication of the extent to which health problems might push accumulated investment assets below a critical threshold. For the purpose of this study, investment assets include stocks, bonds, certificates of deposit, individual retirement accounts, real estate, and business or farm equity, but not the primary residence or vehicles. This definition follows that used by Baek and DeVaney (2004). Net worth is defined as total assets minus total debts.

To measure a change in financial strain, we construct a dummy variable that equals one for each financial ratio guideline if the respondent went from not being financially strained in 2002 to being financially strained in 2004 . To account for the impact that previous financial

\footnotetext{
${ }^{8}$ Recall that Berkowitz and Qiu (2006) found that a change in health status is likely to have a larger impact on older Americans' financial assets rather than non-financial assets, at least in the short run. This finding suggests that a new health condition may be more likely than an existing one to have an impact on liquidity.
} 
strain has on current financial strain, we construct a dummy variable for each ratio to control for whether the respondent reported that the household was financially strained in 2002.

\section{Health Status Measures}

We measure health status using the following three variables - self-reported health status, mild chronic health conditions, and severe chronic health conditions. Self-reported health is used to control for respondents' subjective perceptions of their health status while chronic conditions are used to more objectively capture health status by controlling for specific health conditions (Wallace and Herzog 1995). Respondents are classified as being in poor health using the selfreported health measure if they reported being in either "poor" or "fair" health. They are classified as not being in poor health if they responded that they were in "good," "very good," or "excellent" health. A dummy variable was created to control for this measure of self-reported health. A large body of literature has found that this dichotomous measure of self-reported health status is reliable (i.e., Baker, Stabile, and Deri 2001; Meer, Miller, and Rosen 2003). ${ }^{9}$

The HRS also includes information on eight types of chronic health conditions that commonly occur in later life. They include diabetes, cancer, lung disease, heart condition, stroke, high blood pressure, psychiatric problems, including emotional or nervous conditions, and arthritis. These eight conditions can be divided into two groups based on their severity and the associated financial burden (Wallace and Herzog 1995; Smith 1999): the first five are severe conditions and the rest are mild conditions. To measure the impact of severe or mild chronic

\footnotetext{
${ }^{9}$ To test the robustness of our results to our definition of self-reported health, we defined poor health to include only those respondents who reported being in "poor" health, excluding those who reported being in "fair" health. Our findings were robust to changes in the definition of self-reported health.
} 
conditions on financial strain, we create binary variables to control for whether the respondent has, or does not have, a severe or mild chronic condition. ${ }^{10}$

For our two-period analysis, existing health conditions are defined using binary variables for whether the respondent reports being in poor health or has a severe or mild chronic condition in 2002. New health events are defined as follows. For the self-reported health measure, a change in health status represents whether the respondent reported that their health status worsened between 2002 and 2004. ${ }^{11}$ For severe and mild chronic conditions, a change in health status represents whether the respondent reported that they developed a new severe or mild chronic condition between 2002 and 2004. The specification of these variables is consistent with the literature that has used HRS data to capture the exogenous effects of a new health event (i.e., Berkowitz and Qiu 2006; Lee and Kim 2003; Wu 2003).

\section{Other Variables}

The following demographic characteristics are included as controls in our models and are consistent with the literature: age, gender, race/ethnicity, education, homeownership, and employment status. In addition, we include two controls for marital status - whether the respondent was married in 2002 and whether the respondent went from being married in 2002 to unmarried in 2004. Married couples are able to pool resources. Thus, if an individual goes from being married to unmarried, they are likely to experience a shock to their financial situation. The direction of that shock will depend on the distribution of wealth following the marriage. We also control for whether the respondent is living with one of their adult children. Living with an adult

\footnotetext{
${ }^{10}$ Note that mild chronic conditions include psychiatric problems (i.e., emotional or nervous conditions). However, this objective measure of health is based mainly on physical health conditions. The impact that mental or emotional health has on financial strain is not examined in this paper. Rosen and $\mathrm{Wu}$ (2004) included an indicator for mental health in their model. They found that mental health did not drive the effect that self-reported health status had on financial decisions.

${ }^{11}$ The HRS asks respondents the following survey question: "Compared with your health when we talked with you in 2002, would you say that your health is better now, about the same, or worse?" We use this question to construct the dummy variable for a new health event for the self-reported measure of health status.
} 
child may reduce the amount that elderly parents need to spend on formal care (i.e., nursing home) and may help to reduce wealth depletion and thus financial strain. ${ }^{12}$

Controls for income, liquid assets, and monetary transfers are also included in our models. Household income and liquid assets are reported using the logarithm of these values in 2002 dollars. Income is measured using a self-reported measure of annual gross income for the household, and liquid assets are defined to be the sum of checking accounts, savings accounts, and money market funds. A binary variable is also included to account for whether the respondent received a lump sum transfer between 2002 and 2004, thus experiencing a positive shock to their financial situation. This variable identifies individuals who received money or property in the form of an inheritance, a trust fund, an insurance settlement, or any other large lump sum payment. Another binary variable is included to control for whether the respondent gave a financial transfer to their child/children between 2002 and 2004. This variable controls for a respondent's bequest motive as well as a reduction in resources between the two time periods.

In addition to these variables, we include a series of categorical variables that control for whether the respondent has supplemental health insurance coverage in addition to Medicare A and B. The first insurance variable controls for having Medicare plus an employer-sponsored insurance plan. The second variable controls for having Medicare plus Medigap, a private insurance plan that fills gaps in coverage by Medicare. The next variable controls for whether the individual is on Medicaid, which is a low-cost version of Medigap provided by the federal government to the poor. The final variable is used to account for whether the respondent has a Medicare HMO plan.

\footnotetext{
${ }^{12}$ Lee and Kim (2003) found that elderly parents who co-resided with their adult children experienced less wealth depletion.
} 
Finally, recall that the instrumental variables for the existing health equation are defined using two measures that control for health behaviors - smoking and exercise. The variable for smoking is equal to one if the respondent currently smokes, and the variable for exercise if equal to one if the respondent participates in vigorous physical activity at least one to three times per month (i.e., running, jogging, swimming, cycling, tennis, other aerobic activity or gym workout, heavy housework, or other physical labor).

\section{DESCRIPTIVE STATISTICS}

Older Americans were identified as being "financially strained" if they fell under one or more of the three financial guidelines. In 2004, 39.6 percent of the sample was classified as financially strained because they met only one guideline, 27.7 percent met two of the three guidelines, and 4.2 percent met all three guidelines. Approximately 28.6 percent of the sample was classified as not being financially strained, because they did not meet any of the guidelines.

Table 1 provides insight into the relationship between financial strain and health status. The top half of the table presents statistics for respondents who were financially strained in 2004 while the bottom half looks at respondents who went from not being financially strained in 2002 to being financially strained in 2004. Standard chi-square tests were used to identify differences in means that were significant between strained and unstrained respondents. For the entire sample, the percentage of older respondents who reported being insolvent in 2004 was 5.1 percent, while those who reported being illiquid and having insufficient investments assets were 50.1 and 52.2 percent, respectively. With respect to health status, 26.4 percent reported having poor health in 2002, 83.9 percent reported having a mild chronic condition and 55.8 percent reported having a severe chronic condition. The percentage of respondents who reported that their health status had worsened between 2002 and 2004 was 30.7 percent. However, fewer 
respondents reported developing a new mild or severe chronic condition - only 3.9 and 6.6 percent, respectively.

With respect to the relationship between health and financial strain, older respondents who had poor health in 2002 were more likely to be financially strained as were those who reported that their health status had worsened between 2002 and 2004 . We also found that those who were financially strained in 2002 were more likely to be strained in 2004 . Those who were financially strained in 2004 according to one measure were also more likely to be financially strained according to the other measures. For instance, those who were illiquid in 2004 were more likely than those who were liquid to be insolvent ( 8.6 percent compared to 1.5 percent) and to have insufficient investment assets (61.8 percent compared to 42.5 percent).

When looking at changes in financial strain between 2002 and 2004, we found fewer statistical differences between strained and unstrained respondents. A plausible explanation is that the percentage of respondents who experienced a change in financial strain was relatively small. Only 2.7 percent of the sample reported going from solvency to insolvency, 16.1 percent reported going from being liquid to illiquid, and 11.1 percent reported that they went from sufficient to insufficient investment assets.

The descriptive statistics for respondents who reported being financially strained in 2004 are presented in Table 2. The following are key points to note. First, respondents who were financially strained in 2004 were more likely than those who were not strained to report lower levels of income, liquid assets, and net worth. In addition, they were less likely to have received a lump sum of money and to have made a financial transfer to their children. Demographically, respondents who were financially strained were more likely to be black or Hispanic and living with one of their children. They had less education and were less likely to be married and to be a 
homeowner. With respect to insurance, financially strained respondents were more likely to be a Medicaid beneficiary and less likely to have additional health insurance coverage such as Medigap or employer-sponsored private insurance. We now examine the extent to which the regression results support these preliminary statistics.

\section{RESULTS}

\section{Two-stage Multivariate Analysis}

In the first stage, we estimated Equation (3) to obtain predicted values for prior health status for each of the three health measures: 1) self-reported poor health, 2) having a mild chronic condition, and 3) having a severe chronic condition. The results for the instrumental variables showed that exercise was a significant predictor of health status such that those who regularly exercised were less likely to be in poor health. Smoking was not found to be statistically significant. We tested the validity of the instrumental variable, exercise, using two standard conditions: (1) $\operatorname{corr}\left(E_{t-1}, H_{t-1}\right) \neq 0$ and (2) $\operatorname{corr}\left(E_{t-1}, u_{t-1}\right)=0$. For the first condition, we checked whether exercise was significantly correlated with health status and found that it was. For the second condition, we regressed the residuals from the health equation on exercise, along with other control variables to see if the coefficient on exercise was statistically equal to zero. The coefficient was equal to zero for all of our models, indicating no relationship between exercise and financial strain. Based on these tests, we concluded that exercise was a valid instrumental variable for our study (Stock and Watson 2006). The results from the first stage and the validity tests are available from the authors upon request.

Table 3 presents the results from the second-stage probit model (see Equation 4), which shows how the probability of being financially strained in 2004 was affected by self-reported health status in 2002 and changes in self-reported health status between 2002 and 2004. For all 
three measures of financial strain, the results showed that having poor health in 2002 significantly increased the likelihood that older individuals experienced financial strain in 2004. Those who reported that their health had worsened between 2002 and 2004 were also more likely to be financially strained, but this finding was only significant for the solvency ratio.

Demographically, we found the results to be similar for the three measures of financial strain, yet slightly different. Being black or Hispanic and living with a child increased the probability of being financially strained for all three measures. However, additional years of education significantly decreased the probability of being illiquid and having insufficient investment assets while working (part-time or full-time) increased the probability of strain for these two measures. Being a homeowner significantly decreased the probability of being insolvent and illiquid. It also decreased the probability of having insufficient investment assets, but this finding was not statistically significant. Receiving a lump sum transfer between 2002 and 2004 also decreased the probability of financial strain for all three measures but was only significant for the liquidity measure.

With respect to the insurance variables, we found that having supplemental health insurance in 2002 from an employer-sponsored insurance plan or Medigap significantly decreased the probability of financial strain. However, being a beneficiary of Medicaid in 2002 significantly decreased the probability of being insolvent while it increased the probability of being illiquid and having insufficient investment assets. This is likely a function of the eligibility requirements for Medicaid, which targets the poor and is based on a household's income and asset holdings. Finally, those who were financially strained in 2002 were also significantly more likely to be financially strained in 2004 . 
Table 4 presents the results from the second-stage probit model, where we used having a severe chronic condition as the measure of health status. Once again, we found that having poor health in 2002 (i.e., having a severe chronic condition) significantly increased the likelihood of being financial strained in 2004 for all three measures. The probability of financial strain also increased for those who reported that they developed a new severe chronic health condition between 2002 and 2004. However, this finding was only mildly significant for the solvency ratio $(p<.10)$. With respect to the demographic statistics, the results were fairly consistent with those presented in Table 3.

We also estimated the models for whether an individual had a mild chronic condition. The results showed that having a mild chronic condition in 2002 significantly increased the probability of being illiquid in 2004 but did not have a significant impact on the other two measures of financial strain. Those who reported that they developed a new mild chronic condition between 2002 and 2004 were significantly more likely to have insufficient investment assets. However, there was little evidence that a new mild chronic condition affected solvency or liquidity. The regression results for these models are available from the authors upon request.

Finally, as a second longitudinal approach, we re-estimated all of our models to investigate whether an existing health condition or a new health event resulted in a change in financial strain between 2002 and 2004. Only a few variables were found to be significant, and those variables only pertained to the solvency ratio. Specifically, we found that those who reported having poor health in 2002 or whose health had worsened between 2002 and 2004 were significantly more likely to report that they had gone from being solvent in 2002 to insolvent in 2004. In addition, the results showed that having a severe chronic condition in 2002 significantly 
increased the probability of going from solvency to insolvency while developing a new severe chronic condition did not. These results are also available upon request.

\section{Marginal Effects for Changes in Health Status}

Table 5 summarizes the results from all of the models by presenting the marginal effects for the three measures of health status according to financial strain in 2004 and changes in financial strain between 2002 and 2004. Marginal effects were calculated at the weighted sample means. The predicted probabilities for being in poor health also are reported and provide the baseline probabilities that were used to calculate the marginal effects.

In comparing the magnitudes of the various marginal effects, several findings are worth noting. First, the effect of existing self-reported health on current financial strain appeared to be largest for the investment assets ratio. Being in poor health in 2002 significantly increased the probability of having insufficient investment assets in 2004 by 7.4 percentage points while only increasing the probability of insolvency by 1.6 percentage points and the probability of illiquidity by 3.8 percentage points.

Second, the largest effects on financial strain were found for those who had severe health conditions. Specifically, a severe health condition in 2002 increased the probability of insolvency in 2004 by 3.3 percentage points, compared to only 1.6 percentage points for the self-reported measure of poor health. In addition, a severe health condition in 2002 increased the probability of being illiquid in 2004 by 10.2 percentage points (compared to 3.8 for self-reported poor health), and of having insufficient investment assets by 19.6 percentage points (compared to 7.4, respectively).

Third, the marginal effect of having an existing mild chronic condition was only significant for the liquidity ratio. Interestingly, the magnitude of the effect was similar to that for 
having an existing severe chronic condition. Specifically, having a mild condition in 2002 increased the probability of being illiquid by 13.5 percentage points compared to 10.2 for having a severe condition.

Fourth, the effects of new health events on financial strain were found to be mostly insignificant, except for the solvency ratio. Yet, even for the solvency ratio, the magnitudes of the effects were relatively small. Those who reported that their health worsened or that they had developed a new severe chronic condition between 2002 and 2004 were 1.2 and 1.1 percentage points more likely to be insolvent in 2004, respectively. The exception was for the investment assets ratio, which showed that those who reported a new mild chronic condition between 2002 and 2004 were 7.7 percentage points more likely to have insufficient investment assets in 2004 .

Finally, we look at the impact that health had on changes in financial strain between 2002 and 2004. The marginal effects were mostly insignificant, except for the solvency ratio, and even then the effects were relatively small in magnitude. For example, an existing health condition in 2002 resulted in a 1.1 percentage point increase in individuals going from being solvent in 2002 to insolvent in 2004 compared to a 1.6 percentage increase in being insolvent in 2004 regardless of prior solvency status. The same finding continues to hold true for existing severe chronic conditions, where the percentage point increases were 2.5 and 3.3 , respectively.

\section{DISCUSSION}

\section{What Have We Learned?}

This study used data from the 2002 and 2004 Health and Retirement Study to investigate how health problems affect the financial strain of older Americans. We used three financial ratio guidelines that take into consideration a household's level of solvency, liquidity, and investment asset accumulation. We tested our models using a subjective measure of self-reported health 
status and two objective measures of health that controlled for the severity of specific health conditions. In general, the results showed that health problems increased the likelihood of financial strain for older Americans.

The results also showed that the magnitude of the effects varied by the measure of financial strain and how health status was defined. For example, when using self-reported health status, we found that poor health had a larger effect on liquidity and investment asset accumulation than on the degree of solvency. The magnitude of the effect of poor health on financial strain was even larger for respondents who had severe chronic conditions. Lower levels of investment assets suggest that households are trading expected future return for consumption certainty and liquidity. When an individual becomes ill, it is often not an instantaneous and unexpected event. If an individual is in declining health, a rational response would be to convert illiquid assets into more liquid assets. Thus one would expect individuals dealing with a negative health event to experience larger drops in investment assets than in liquid assets. If individuals have adequately planned for health care expenditures during retirement, these expenses are not likely to affect their solvency unless they develop a serious and long-term health condition that results in them also having to borrow. However, even in these instances, investment assets and liquidity would likely be affected more than solvency by a negative health event.

Another key result was that existing health conditions were more likely to increase financial strain than new health events. However, when new health events affected financial strain, they tended to have the most significant impact on solvency. As previously mentioned, a health problem does not often occur instantaneously and unexpectedly. Thus, individuals have time to liquidate investment assets and shift their portfolios to more liquid assets, which may result in the individual eventually experiencing financial strain. However, a more sudden onset 
of serious illness would likely leave an individual less time to prepare financially. They may be unable to quickly liquidate their investment assets, and they may have to borrow, perhaps against their home. This would also provide a plausible explanation for why we found that health status had little effect on changes in financial strain, except to the extent that health had an immediate and negative impact on solvency.

In addition to these results, we found that having some type of supplemental health insurance coverage significantly mitigated financial strain for older individuals. This result reflects how critical it is that older Americans maintain adequate health insurance coverage, especially to pay for health care expenses that are not covered by Medicare. Also, recall that beneficiaries of Medicaid were more likely to be illiquid and to have insufficient investment assets, but less likely to be insolvent. Since Medicaid is a means-tested program (e.g., only individuals with very low income and asset holdings qualify), this finding may simply reflect low financial resources rather than lower levels of financial strain.

\section{Implications for Researchers and Consumers}

Overall, the findings from this study have important implications for research related to the health and financial security of older Americans. Previous studies have focused on using primarily income and wealth to measure the financial burden of health problems for older populations. Yet, these measures do not adequately capture the extent to which poor health results in financial strain and how negative health events might affect financial portfolios. We have shown that financial ratio guidelines (i.e., solvency, liquidity, and investment asset accumulation ratios) can provide a more comprehensive look at how poor health can affect the overall financial security of the household. Specifically, we find evidence that negative health events, especially severe existing conditions, can result in serious financial strain. They may also 
result in portfolios shifts, where individuals generate liquidity by reducing their holdings of investment assets. Our findings also show that using both subjective and objective health measures can provide a clearer picture of which individuals in poor health are likely to experience the greatest financial burden (i.e., those with severe existing conditions).

Our results also have important implications for aging consumers. As the U.S. population continues to age and health care costs continue to rise, individuals are likely to see larger shares of their retirement savings going toward health care expenditures. The end result is that more individuals are likely to experience financial strain. For older individuals who have not adequately saved for retirement, a severe chronic condition could result in rapid wealth depletion, resulting in serious financial strain such as insolvency.

\section{Educational Opportunities}

Financial education can help future retirees better prepare for rising health care costs and avoid unnecessary financial burden in later life. In particular, financial professionals and educators may want to provide individuals with a better understanding of how negative health events can affect their financial portfolios and how to shift their assets to hedge against serious financial strain. Also, it would be useful for individuals to have more guidance on how to build future health care expenditures into their existing savings and retirement plans so that they are setting aside an adequate amount in a "health care fund." In addition, consumers would likely benefit from more information about supplemental health insurance plans and the critical role they play in reducing financial strain that results from health problems. Given the scope of this paper, we were unable to address issues related to long-term care planning. However, financial professionals and educators may also want to provide more information about the range of medical, personal and social services available to those who are unable to provide for their own 
needs for an extended period of time. Finally, for those working with particularly vulnerable subgroups of older Americans (i.e., low-income individuals who have little or no retirement savings), there may be opportunities to provide education about low-cost medical services and insurance plans as well as government support programs such as Medicaid. All of these educational measures could help older Americans cope with the potentially debilitating effects that health problems could have on their overall financial security. 


\section{REFERENCES}

Adams, Peter, Michael D. Hurd, Daniel McFadden, Angela Merrill, and Tiago Ribeiro. 2003. Healthy, Wealthy, and Wise? Tests for Direct Causal Paths Between Health and Socioeconomic Status. Journal of Econometrics, 112 (1): 3-56.

Baek, Eunyoung and Sharon A. DeVaney. 2004. Assessing the Baby Boomers' Financial Wellness Using Financial Ratios and a Subjective Measure. Family and Consumer Sciences Research Journal, 32 (4): 321-348.

Baker, Michael, Mark Stabile, and Catherine Deri. 2001. What Do Self-Reported, Objective, Measures of Health Measure? (NBER Working Paper No. 8419). Cambridge, MA: National Bureau of Economic Research.

Barsky, Robert B., F. Thomas Juster, Miles S. Kimball, and Matthew D. Shapiro. 1997. Preference Parameters and Behavioral Heterogeneity: An Experimental Approach in the Health and Retirement Study. Quarterly Journal of Economics, 112 (2): 537-579.

Berkowitz, Michael K. and Jiaping Qiu. 2006. A Further Look at Household Portfolio Choice and Health Status. Journal of Banking and Finance, 30 (4): 1201-1217.

Chang, Y. Regina, Sherman D. Hanna, and Xiaojing J. Fan. 1997. Emergency Fund Levels: Is Household Behavior Rational? Financial Counseling and Planning Journal, 8 (1): 47-55.

Copeland, Craig. 2006. Debt of the Elderly and Near Elderly, 1992-2004. Employee Benefit Research Institute Notes, 27 (9): 16 pp. Retrieved September 28, 2006, from http://www.ebri.org/publications/notes/

Crystal, Stephen, Richard W. Johnson, Jeffrey Harman, Usha Sambamoorthi, and Rizie Kumar. 2000. Out-of-Health Care Costs Among Older Americans. Journal of Gerontology: Social Sciences, 55B (1): S51-S62.

DeVaney, Sharon A. 1994. The Usefulness of Financial Ratios as Predictors of Household Insolvency: Two Perspectives. Financial Counseling and Planning Journal, 5 (1): 5-24.

DeVaney, Sharon A. 2000. Using Financial Ratios. In E. Thomas Garman, Jing J. Xiao, and Bruce G. Brunson (Eds.), The Mathematics of Personal Financial Planning: Using Calculators and Computers ( $3^{\text {rd }}$ ed., pp.147-161). Cincinnati, OH: Thomson Publishing.

DeVaney, Sharon A. and Ruth Lytton. 1995. Household Insolvency: A Review of Household Debt Repayment, Delinquency, and Bankruptcy. Financial Services Review, 4 (2): 137156.

Drentea, Patricia and Paul J. Lavrakas. 2000. Over the Limit: The Association among Health, Race and Debt. Social Science and Medicine, 50 (4): 517-529. 
Ezzati-Rice, Trena M., David Kashihara, and Steven R. Machlin. 2004. Health Care Expenses in the United States, 2000 (AHRQ Publication No.04-0022). Rockville, MD: Agency for Healthcare Research and Quality, U.S. Department of Health and Human Services Retrieved March 6, 2007, from http://www.meps.ahrq.gov/mepsweb/data_files/publications/rf21/rf21.shtml

Garman, E. Thomas and Raymond E. Forgue. 2006. Personal Finance. $8^{\text {th }}$ edition. Boston, MA: Houghton Mifflin Company.

Haider, Steven, Michael Hurd, Elaine Reardon, and Stephanie Williamson. 2000. Patterns of Dissaving in Retirement, \#2000-10. Washington D.C.: AARP Public Policy Institute. Retrieved February 15, 2007, from http://www.aarp.org/research/financial/retirementsaving/aresearch-import-238-200010.html

Heeringa, S. G. and Judith H. Connor. 1995. Technical Description of the Health and Retirement Survey Sample Design (Public Use Version). Ann Arbor, MI: Institute for Social Research, University of Michigan. Retrieved February 15, 2007, from http://hrsonline.isr.umich.edu/docs/userg/HRSSAMP.pdf

Hoeymans, N., E. Feskens, D. Kromhout, and G. Van Den Bos. 1997. Ageing and the Relationship Between Functional Status and Self-Rated Health in Elderly Men. Social Science \& Medicine, 45 (10): 1527-1536.

Hurd, Michael D. 1990. Research on the Elderly: Economic Status, Retirement, and Consumption and Saving. Journal of Economic Literature, 28 (2): 565-637.

Hurd, Michael D. and Arie Kapteyn. 2003. Health, Wealth, and the Role of Institutions (Labor and Population Program, Working Paper Series 03-09). Santa Monica, CA: Rand Corporation.

Hurd, Michael D. and Kathleen McGarry. 1997. Medical Insurance and the Use of Health Care Services by the Elderly. Journal of Health Economics, 16 (2): 129-154.

Idler, Ellen and Yael Benyamini. 1997. Self-Related Health and Mortality: A Review of TwentySeven Community Studies. Journal of Health and Social Behavior, 38 (1): 21-37.

Idler, Ellen and Stanislav Kasl. 1991. Health Perceptions and Survival: Do Global Evaluations of Health Status Really Predict Mortality? Journal of Gerontology: Social Sciences, 46 (2): S55-S65.

Idler, Ellen and Stanislav Kasl. 1995. Self-Ratings of Health: Do They Also Predict Change in Functional Ability? Journal of Gerontology, 50B (suppl): S344-S353.

Jacoby, Melissa B. 2002. Does Indebtedness Influence Health? A Preliminary Inquiry. Journal of Law, Medicine \& Ethics, 30 (4): 560-571. 
Johnson, Richard W. and Rudolph G. Penner. 2004. Will Health Care Costs Erode Retirement Security? Issue in Brief, Number 23. Chestnut Hill, MA: Center for Retirement Research at Boston College.

Kim, Hyungsoo and Jinkook Lee. 2005. Unequal Effects of Elders' Health Problems on Wealth Depletion across Race and Ethnicity. The Journal of Consumer Affairs, 39 (1): 148-172.

Kutty, Nandinee K. 1999. Demand for Home Modifications: A Household Production Approach. Applied Economics, 31 (10): 1273-1281.

Lee, Jinkook and Hyungsoo Kim. 2003. An Examination of the Impact of Health on Wealth Depletion in Elderly Individuals. Journal of Gerontology: Social Sciences, 58B (2): S120-S126.

Lillard, Lee A. and Yoram Weiss. 1997. Uncertain Health and Survival: Effects on End-of-Life Consumption. Journal of Business \& Economic Statistics, 15 (2): 254-268.

Lyons, Angela C. and Tansel Yilmazer. 2005. Health and Financial Strain: Evidence from the Survey of Consumer Finances. Southern Economic Journal, 71 (4): 873-890.

Lytton, Ruth H., E. Thomas Garman, and Nancy M. Porter. 1991. How to Use Financial Ratios When Advising Clients. Financial Counseling and Planning, 2 (1): 3-23.

Meer, Jonathan, Douglas L. Miller, and Harvey S. Rosen. 2003. Exploring the Health-Wealth Nexus. Journal of Health Economics, 22 (5): 713-730.

Michaud, Pierre-Carl and Arthur van Soest. 2004. Health and Wealth of Elderly Couples: Causality Tests Using Dynamic Panel Data Models (RAND working paper WR-191). Santa Monica, CA: RAND Corporation.

Modigliani, Franco and Richard Brumberg. 1954. Utility Analysis and the Consumption Function: An interpretation of Cross-Section Data. In Post-Keynesian Economics, edited by K. K. Kurihara. New Brunswick, NJ: Rutgers University Press.

Rosen, Harvey S. and Stephen Wu. 2004. Portfolio Choice and Health Status. Journal of Financial Economics, 72 (3): 457-484.

Smith, James P. 1997. The Changing Economic Circumstances of the Elderly: Income, Wealth, and Social Security (Policy Brief No.8). Syracuse, NY: Maxwell School of Citizenship and Public Affairs, Syracuse University.

Smith, James P. 1999. Healthy Bodies and Thick Wallets: The Dual Relation Between Health and Economic Status. Journal of Economic Perspectives, 13 (2): 145-166. 
Smith, James P. 2003. Consequences and Predictors of New Health Events. In Analyses in the Economics of Aging, edited by David A. Wise (pp. 213-237). Chicago, IL: University of Chicago Press.

Stock, James H. and Mark W. Watson. 2006. Introduction to Econometrics. 2nd edition. Upper Saddle River, NJ: Pearson Education.

Wallace, Robert B. and A. Regula Herzog. 1995. Overview of the Health Measures in the Health and Retirement Study. The Journal of Human Resources, 30 (Supplement): S84-S107.

Wu, Stephen. 2003. The Effects of Health Events on the Economic Status of Married Couples. The Journal of Human Resources, 38 (1): 219-231.

Yao, Rui, Sherman D. Hanna, and Catherine P. Montalto. 2003. The Capital Accumulation Ratio as an Indicator of Retirement Adequacy. Financial Counseling and Planning Journal, 14 (2): $1-11$.

Zeldes, Stephen. 1989. Consumption and Liquidity Constraints: An Empirical Investigation. Journal of Political Economy, 97 (2): 305-46. 
TABLE 1

Relationship Between Financial Strain and Health Status for 2002 and 2004 (HRS, N=9,394)

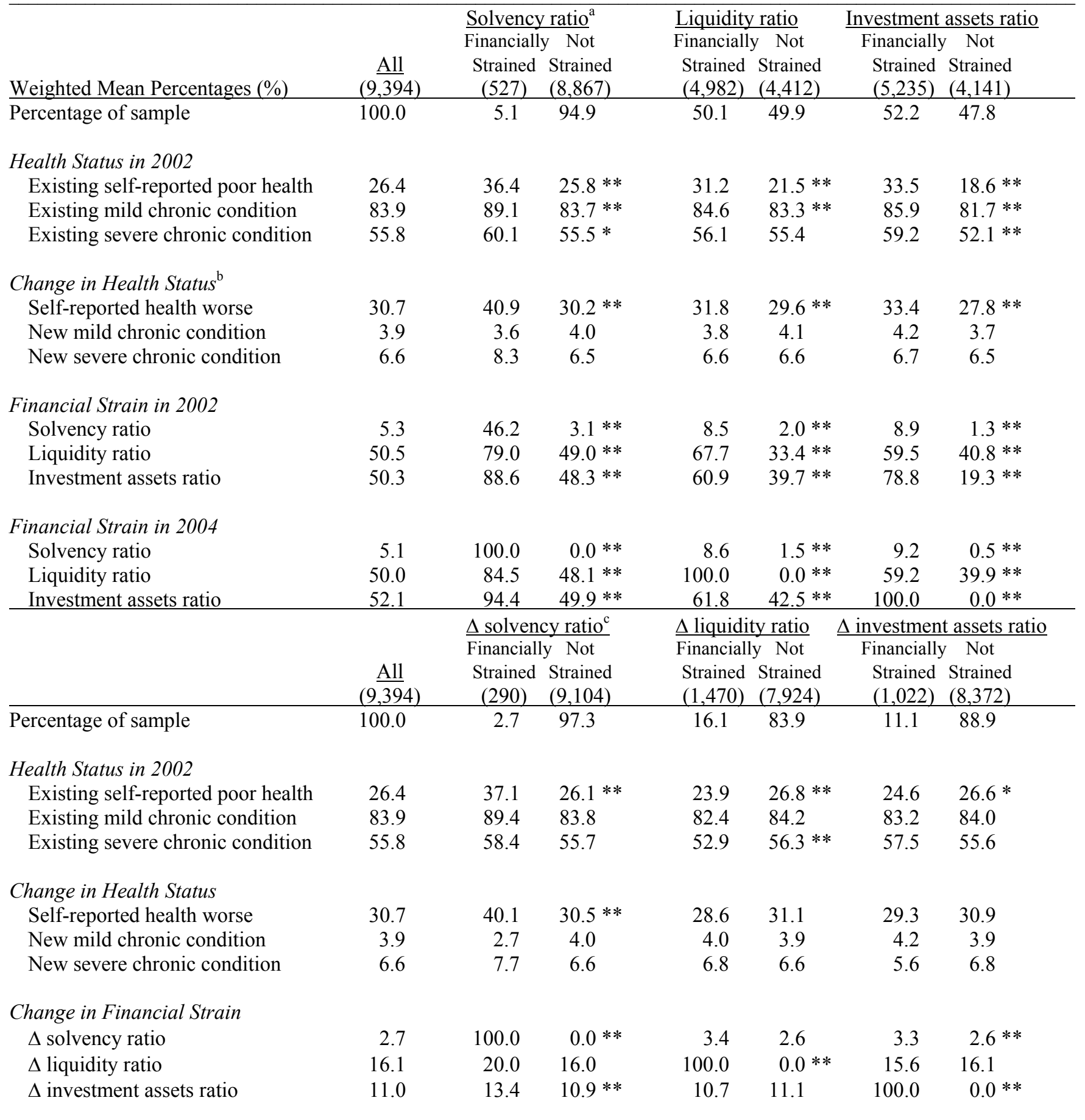

${ }^{a}$ For each measure of financial strain, we compare respondents who were financially strained in 2004 to respondents who were not financially strained in 2004. The "solvency ratio" represents the percentage of households with assets/debts $<1.0$. The "liquidity ratio" represents the percentage of households with liquid assets/monthly income $<2.5$. The "investment assets ratio" represents the percentage of households with investment assets/net worth $<0.25$.

${ }^{\mathrm{b}}$ A change in health status represents the percentage of respondents who either reported that their health status worsened between 2002 and 2004 or they developed a new mild or new chronic health condition.

${ }^{c}$ A change in financial strain represents the percentage of households who went from not being financially strained in 2002 to being financially strained in 2004 according to each financial ratio guideline.

${ }^{*} \mathrm{p}<0.10 ; * * \mathrm{p}<0.05 ; * * \mathrm{p}<0.01$ 
TABLE 2

Descriptive Statistics for 2004 Financial Strain Measures (HRS, N=9,394)

\begin{tabular}{|c|c|c|c|c|c|c|c|}
\hline \multirow[b]{2}{*}{ Weighted Mean Values } & \multirow[b]{2}{*}{$\left(9, \frac{\text { All }}{394)}\right.$} & \multicolumn{2}{|c|}{$\underline{\text { Solvency ratio }}^{\mathrm{a}}$} & \multicolumn{2}{|c|}{$\underline{\text { Liquidity ratio }}$} & \multicolumn{2}{|c|}{ Investment assets ratio } \\
\hline & & $\begin{array}{c}\text { Financially } \\
\text { Strained } \\
(527)\end{array}$ & $\begin{array}{c}\text { Not } \\
\text { Strained } \\
(8,867) \\
\end{array}$ & $\begin{array}{c}\text { Financially } \\
\text { Strained } \\
(4,982)\end{array}$ & $\begin{array}{c}\text { Not } \\
\text { Strained } \\
(4,412) \\
\end{array}$ & $\begin{array}{c}\text { Financially } \\
\text { Strained } \\
(5,235) \\
\end{array}$ & $\begin{array}{c}\text { Not } \\
\text { Strained } \\
(4,141) \\
\end{array}$ \\
\hline \multicolumn{8}{|l|}{ Income and Wealth $(\$ 1,000)$} \\
\hline Household income (2002) & 46.4 & 29.8 & $47.3 * *$ & 42.0 & $50.7 * *$ & 29.7 & $64.6 * *$ \\
\hline Liquid assets (2002) & 34.9 & 5.1 & $36.6 * *$ & 16.4 & $53.5 * *$ & 27.0 & $43.7 * *$ \\
\hline Net worth $(2002)$ & 410.5 & 106.3 & $427.0 * *$ & 315.2 & $505.9 * *$ & 187.7 & $654.3 * *$ \\
\hline Receive lump sum (2002-2004) & 4.6 & 3.5 & $4.6 *$ & 2.7 & $6.5 * *$ & 3.2 & $6.1 * *$ \\
\hline Transfer to child (2002-2004) & 30.0 & 21.7 & $30.4 * *$ & 26.2 & $33.7 * *$ & 22.9 & $37.7 * *$ \\
\hline \multicolumn{8}{|l|}{ Demographics } \\
\hline Age (in years) (2002) & 74.1 & 71.5 & $74.3 * *$ & 73.5 & $74.7 * *$ & 74.5 & $73.8 * *$ \\
\hline Female & 58.3 & 58.7 & 58.3 & 58.5 & 58.1 & 62.7 & $53.6 * *$ \\
\hline Black or Hispanic & 14.0 & 27.5 & $13.3 * *$ & 21.4 & $6.7 * *$ & 22.3 & $5.1 * *$ \\
\hline Yrs of education (2002) & 12.1 & 11.5 & 12.1 & 11.5 & $12.6 * *$ & 11.1 & $13.2 * *$ \\
\hline Married (2002) & 57.4 & 55.5 & 57.5 & 54.4 & $60.4 * *$ & 48.0 & $67.5 * *$ \\
\hline Change in married status (2002-2004) & 3.7 & 3.2 & 3.8 & 3.4 & $4.1 * *$ & 3.9 & 3.6 \\
\hline Living with a child (2002) & 15.8 & 27.5 & $15.2 * *$ & 19.2 & $12.4 * *$ & 20.9 & $10.3 * *$ \\
\hline Homeowner (2002) & 72.7 & 61.6 & $73.3 * *$ & 65.7 & $79.6 * *$ & 66.7 & $79.1 * *$ \\
\hline Working (full- and part-time) (2002) & 18.0 & 24.1 & $17.6 * *$ & 19.2 & $16.7 * *$ & 16.6 & $19.4 * *$ \\
\hline \multicolumn{8}{|l|}{ Health Insurance ${ }^{\mathrm{b}}$} \\
\hline Medicare A and B only (2002) & 14.7 & 25.6 & $14.1 * *$ & 17.6 & $11.7 * *$ & 18.4 & $10.8 * *$ \\
\hline Medicare+ Employer insurance (2002) & 32.9 & 26.2 & $33.3 * *$ & 29.2 & $36.7 * *$ & 26.5 & $39.9 * *$ \\
\hline Medicare + Medigap (2002) & 31.5 & 23.3 & $31.9 * *$ & 27.4 & $35.5 * *$ & 27.7 & $35.6 * *$ \\
\hline Medicare+ Medicaid (2002) & 7.1 & 10.2 & $6.9 * *$ & 12.1 & $1.9 * *$ & 12.6 & $1.0 * *$ \\
\hline Medicare HMO (2002) & 13.8 & 14.7 & $13.8 * *$ & 13.4 & $14.2 * *$ & 14.8 & $12.7 * *$ \\
\hline
\end{tabular}

${ }^{a}$ For each measure of financial strain, we compare respondents who were financially strained in 2004 to respondents who were not financially strained in 2004. The "solvency ratio" represents the percentage of households with assets/debts $<1.0$. The "liquidity ratio" represents the percentage of households with liquid assets/monthly income $<2.5$. The "investment assets ratio" represents the percentage of households with investment assets/net worth $<0.25$.

${ }^{\mathrm{b}}$ Note that the health insurance variables sum to $100 \%$, and the chi2 test was conducted on the entire set of dummy variables.

$* \mathrm{p}<0.10 ; * * \mathrm{p}<0.05 ; * * * \mathrm{p}<0.01$ 
TABLE 3

Two-Stage Probit Models: Effect of Self-Reported Health on Probability of Financial Strain in 2004 (HRS, N=9,394)

\begin{tabular}{|c|c|c|c|c|c|c|}
\hline \multirow[b]{3}{*}{$\underline{\text { Variable }}$} & \multicolumn{6}{|c|}{ Measures of Financial Strain (2004) } \\
\hline & \multicolumn{2}{|c|}{$\underline{\text { Solvency Ratio }}$} & \multicolumn{2}{|c|}{ Liquidity Ratio } & \multicolumn{2}{|c|}{ Investment Assets Ratio } \\
\hline & Coeff & $\mathrm{SE}$ & Coeff & $\mathrm{SE}$ & Coeff. & $\mathrm{SE}$ \\
\hline Predicted: Existing self-reported poor health (2002) & 0.229 & $(0.107) * *$ & 0.096 & $(0.053) *$ & 0.191 & $(0.067) * * *$ \\
\hline Self-reported health worse $(2002-2004)$ & 0.178 & $(0.062) * * *$ & 0.020 & $(0.032)$ & 0.039 & (0.039) \\
\hline Log (household income) (2002) & -0.011 & $(0.024)$ &.---- & $(-.---)$ & -0.158 & $(0.048) * * *$ \\
\hline Log (liquid assets) (2002) & $--\cdot---$ & $(-.----)$ &.----- & $(-.----)$ & -0.042 & $(0.006) * * *$ \\
\hline Age $(2002)$ & 0.006 & $(0.072)$ & 0.023 & $(0.036)$ & -0.038 & $(0.059)$ \\
\hline $\operatorname{Age}^{2}(2002)$ & -0.000 & $(0.000)$ & -0.000 & $(0.000)$ & 0.000 & $(0.000)$ \\
\hline Female & -0.030 & $(0.057)$ & -0.025 & $(0.026)$ & 0.052 & $(0.029)$ \\
\hline Black or Hispanic & 0.177 & $(0.091) * *$ & 0.352 & $(0.050) * * *$ & 0.228 & $(0.062) * * *$ \\
\hline Yrs of education (2002) & 0.010 & $(0.009)$ & -0.021 & $(0.007) * * *$ & -0.040 & $(0.007) * * *$ \\
\hline Married (2002) & -0.059 & $(0.082)$ & -0.048 & $(0.046)$ & -0.112 & $(0.048) * *$ \\
\hline Change in married status (2002-2004) & 0.085 & $(0.181)$ & -0.018 & $(0.079)$ & 0.045 & $(0.115)$ \\
\hline Living with a child (2002) & 0.169 & $(0.078) * *$ & 0.139 & $(0.050) * * *$ & 0.157 & $(0.055) * * *$ \\
\hline Homeowner (2002) & -0.162 & $(0.074) * *$ & -0.272 & $(0.046) * * *$ & -0.016 & $(0.043)$ \\
\hline Working (2002) & 0.169 & $(0.091)$ & 0.112 & $(0.053) * *$ & 0.201 & $(0.058) * * *$ \\
\hline Receive lump sum (2002-2004) & -0.018 & $(0.159)$ & -0.414 & $(0.097) * * *$ & -0.140 & $(0.105)$ \\
\hline Transfer to child (2002-2004) & -0.162 & $(0.091)$ & -0.058 & $(0.039)$ & -0.085 & $(0.044)$ \\
\hline Medicare+ Employer insurance (2002) & -0.248 & $(0.070) * * *$ & -0.118 & $(0.050) * *$ & -0.030 & $(0.044)$ \\
\hline Medicare+ Medigap (2002) & -0.224 & $(0.085) * *$ & -0.153 & $(0.046) * * *$ & -0.134 & $(0.054) * *$ \\
\hline Medicare+ Medicaid (2002) & -0.453 & $(0.135) * * *$ & 0.427 & $(0.084) * * *$ & 0.281 & $(0.132) * *$ \\
\hline Medicare HMO (2002) & -0.144 & $(0.082)$ & -0.086 & $(0.060)$ & 0.050 & $(0.050)$ \\
\hline Financial strain (2002): solvency ratio & 1.628 & $(0.077) * * *$ & -.---- & $(-.----)$ &.---- & $(-.---)$ \\
\hline Financial strain (2002): liquidity ratio & -.---- & $(-.----)$ & 0.729 & $(0.036) * * *$ & -.---- & $(-.---)$ \\
\hline Financial strain (2002): inv/assets ratio &.----- & $(-.----)$ &.----- & $(-.----)$ & 1.309 & $(0.040) * * *$ \\
\hline Constant & -0.568 & $(2.697)$ & 0.003 & $(1.386)$ & 3.544 & $(2.271)$ \\
\hline No. of positive observations & & 527 & & 4,982 & & 5,235 \\
\hline $\log \mathrm{L}$ & & $-1,562.6$ & & $-5,476.1$ & & $-4,205.5$ \\
\hline Pseudo $\mathrm{R}^{2}$ & & 0.23 & & 0.15 & & 0.34 \\
\hline
\end{tabular}

Note: "Coeff" represents the coefficient estimates for the probit models. Standard errors are reported in parentheses and have been adjusted for sample clustering and stratification. Variables which have a "(2002)" after them are 2002 values; all other variables are 2004 values. The "solvency ratio" represents the percentage of households in 2004 with assets/debts $<1.0$. The "liquidity ratio" represents the percentage of households with liquid assets/monthly income $<2.5$.

The "investment assets ratio" represents the percentage of households with investment assets/net worth $<0.25$. "Change in health worse" represents the percentage of respondents who reported that their health status worsened between 2002 and 2004. Omitted categories include: white, unmarried, and not receiving Medicare.

$* \mathrm{p}<0.10 ; * * \mathrm{p}<0.05 ; * * * \mathrm{p}<0.01$ 
TABLE 4

Two-Stage Probit Models: Effect of Severe Chronic Condition on Probability of Financial Strain in 2004 (HRS, N=9,394)

\begin{tabular}{|c|c|c|c|c|c|c|}
\hline \multirow[b]{3}{*}{$\underline{\text { Variable }}$} & \multicolumn{6}{|c|}{ Measures of Financial Strain (2004) } \\
\hline & \multicolumn{2}{|c|}{$\underline{\text { Solvency Ratio }}$} & \multicolumn{2}{|c|}{ Liquidity Ratio } & \multicolumn{2}{|c|}{ Investment Assets Ratio } \\
\hline & Coeff & $\mathrm{SE}$ & Coeff & $\mathrm{SE}$ & Coeff. & $\mathrm{SE}$ \\
\hline Predicted: Existing severe chronic condition (2002) & 0.476 & $(0.216) * *$ & 0.259 & $(0.107) * *$ & 0.509 & $(0.117) * * *$ \\
\hline New severe chronic condition (2002-2004) & 0.161 & $(0.096) *$ & 0.035 & $(0.064)$ & 0.053 & $(0.072)$ \\
\hline Log (household income) (2002) & -0.023 & $(0.022)$ &.----- & $(-.---)$ & -0.368 & $(0.064) * * *$ \\
\hline Log (liquid assets) (2002) & -.---- & $(-.----)$ &.----- & $(-.----)$ & -0.043 & $(0.010) * * *$ \\
\hline Age (2002) & 0.000 & $(0.072)$ & 0.020 & $(0.036)$ & -0.017 & $(0.056)$ \\
\hline $\operatorname{Age}^{2}(2002)$ & -0.000 & $(0.000)$ & -0.000 & $(0.000)$ & 0.000 & $(0.000)$ \\
\hline Female & 0.115 & $(0.101)$ & 0.055 & $(0.043)$ & 0.224 & $(0.048) * * *$ \\
\hline Black or Hispanic & 0.299 & $(0.097) * * *$ & 0.420 & $(0.053) * * *$ & 0.543 & $(0.061) * * *$ \\
\hline Yrs of education (2002) & 0.003 & $(0.008)$ & -0.023 & $(0.006) * * *$ & -0.062 & $(0.007) * * *$ \\
\hline Married (2002) & -0.039 & $(0.082)$ & -0.039 & $(0.046)$ & -0.100 & $(0.052)$ \\
\hline Change in married status (2002-2004) & 0.078 & $(0.184)$ & -0.017 & $(0.078)$ & 0.139 & $(0.107)$ \\
\hline Living with a child (2002) & 0.136 & $(0.083)$ & 0.118 & $(0.051) * *$ & 0.198 & $(0.054) * * *$ \\
\hline Homeowner (2002) & -0.167 & $(0.074) * *$ & -0.272 & $(0.046) * * *$ & 0.031 & $(0.035)$ \\
\hline Working (2002) & 0.151 & $(0.087)$ & 0.119 & $(0.052) * * *$ & 0.282 & $(0.051) * * *$ \\
\hline Receive lump sum (2002-2004) & -0.019 & $(0.160)$ & -0.414 & $(0.097) * * *$ & -0.147 & $(0.094)$ \\
\hline Transfer to child (2002-2004) & -0.161 & $(0.091)$ & -0.058 & $(0.039)$ & -0.100 & $(0.042) * *$ \\
\hline Medicare+ Employer insurance (2002) & -0.294 & $(0.069) * * *$ & -0.140 & $(0.048) * * *$ & -0.118 & $(0.046) * *$ \\
\hline Medicare+ Medigap (2002) & -0.253 & $(0.084) * * *$ & -0.165 & $(0.045) * * *$ & -0.264 & $(0.049) * * *$ \\
\hline Medicare+ Medicaid (2002) & -0.519 & $(0.147) * * *$ & 0.377 & $(0.087) * * *$ & 0.329 & $(0.128) * *$ \\
\hline Medicare HMO (2002) & -0.196 & $(0.082) * *$ & -0.110 & $(0.058)$ & -0.019 & $(0.051)$ \\
\hline Financial strain (2002): solvency ratio & 1.645 & $(0.076) * * *$ & -.---- & $(-.----)$ & -.---- & $(-----)$ \\
\hline Financial strain (2002): liquidity ratio & -.---- & $(-.----)$ & 0.731 & $(0.036) * * *$ &.----- & $(-.----)$ \\
\hline Financial strain (2002): inv/assets ratio & -.---- & $(-.----)$ & -.---- & $(-.----)$ & 0.096 & $(0.060)$ \\
\hline Constant & -0.209 & $(2.673)$ & 0.131 & $(1.393)$ & 5.733 & $(2.143) * *$ \\
\hline No. of positive observations & & 527 & & 4,982 & & 5,235 \\
\hline $\log \mathrm{L}$ & & $-1,566.8$ & & $-5,476.1$ & & $-5,007.5$ \\
\hline Pseudo $\mathrm{R}^{2}$ & & 0.22 & & 0.15 & & 0.22 \\
\hline
\end{tabular}

Note: "Coeff" represents the coefficient estimates for the probit models. Standard errors are reported in parentheses and have been adjusted for sample clustering and stratification. Variables which have a "(2002)" after them are 2002 values; all other variables are 2004 values. The "solvency ratio" represents the percentage of households in 2004 with assets/debts $<1.0$. The "liquidity ratio" represents the percentage of households with liquid assets/monthly income $<2.5$. The "investment assets ratio" represents the percentage of households with investment assets/net worth $<0.25$. "New severe chronic condition" represents the percentage of respondents who reported that they developed a new chronic health condition between 2002 and 2004 . Omitted categories include: white, unmarried, and not receiving Medicare.

$* \mathrm{p}<0.10 ; *{ }^{*} \mathrm{p}<0.05 ; * * \mathrm{p}<0.01$ 
TABLE 5

Marginal Effects: The Effect of a Change in Health Status on the Probability of a Change in Financial Strain (HRS, N=9,394)

\begin{tabular}{|c|c|c|c|c|c|c|}
\hline & & & Measures of F & nancial Strai & & \\
\hline & $\underline{\text { Solven }}$ & cy Ratio & Liquidi & y Ratio & $\underline{\text { Investment }}$ & Assets Ratio \\
\hline Models & $\begin{array}{l}\text { Marginal } \\
\text { Effect }^{\mathrm{b}}\end{array}$ & $\begin{array}{c}\text { Predicted } \\
\text { Probability }\end{array}$ & $\begin{array}{l}\text { Marginal } \\
\text { Effect }\end{array}$ & $\begin{array}{c}\text { Predicted } \\
\text { Probability }\end{array}$ & $\begin{array}{c}\text { Marginal } \\
\text { Effect }\end{array}$ & $\begin{array}{c}\text { Predicted } \\
\text { Probability }\end{array}$ \\
\hline Existing self-reported poor health (2002) & $0.016 * *$ & 0.031 & $0.038 *$ & 0.537 & $0.074 * * *$ & 0.597 \\
\hline Self-reported health worse (2002-2004) & $0.012 * * *$ & & 0.008 & & 0.015 & \\
\hline Existing mild chronic condition (2002) & 0.018 & 0.031 & $0.135 * * *$ & 0.537 & 0.049 & 0.597 \\
\hline New mild chronic condition (2002-2004) & 0.000 & & -0.017 & & $0.077 * *$ & \\
\hline Existing severe chronic condition (2002) & $0.033 * *$ & 0.031 & $0.102 * *$ & 0.537 & $0.196 * * *$ & 0.597 \\
\hline New severe chronic condition $(2002-2004)$ & $0.011 *$ & & 0.014 & & 0.020 & \\
\hline & & & Change in Fir & ancial Strain & & \\
\hline & $\underline{\Delta \text { Solve }}$ & ncy Ratio & $\Delta$ Liquic & ity Ratio & $\Delta$ Investmen & Assets Ratio \\
\hline Models & $\begin{array}{l}\text { Marginal } \\
\text { Effect }\end{array}$ & $\begin{array}{c}\text { Predicted } \\
\text { Probability }\end{array}$ & $\begin{array}{l}\text { Marginal } \\
\text { Effect }\end{array}$ & $\begin{array}{c}\text { Predicted } \\
\text { Probability }\end{array}$ & $\begin{array}{c}\text { Marginal } \\
\text { Effect }\end{array}$ & $\begin{array}{c}\text { Predicted } \\
\text { Probability }\end{array}$ \\
\hline Existing self-reported poor health (2002) & $0.011 * *$ & 0.021 & 0.004 & 0.153 & 0.004 & 0.099 \\
\hline Self-reported health worse (2002-2004) & $0.010 * * *$ & & -0.012 & & -0.005 & \\
\hline Existing mild chronic condition (2002) & 0.015 & 0.022 & 0.047 & 0.153 & -0.010 & 0.099 \\
\hline New mild chronic condition (2002-2004) & -0.007 & & 0.007 & & 0.006 & \\
\hline Existing severe chronic condition (2002) & $0.025 * *$ & 0.022 & 0.018 & 0.154 & 0.000 & 0.099 \\
\hline New severe chronic condition $(2002-2004)$ & 0.004 & & 0.004 & & -0.019 & \\
\hline $\begin{array}{l}\text { The "solvency ratio" represents the percen } \\
\text { liquid assets/monthly income }<2.5 \text {. The "in } \\
\text { b Marginal effects have been calculated at th } \\
\text { c The predicted probability of being under fi } \\
\text { d A change in financial strain represents the } \\
\text { according to each financial ratio guideline. } \\
{ }^{*} p<0.10 ; * * p<0.05 ; * * * p<0.01\end{array}$ & $\begin{array}{l}\text { households } \\
\text { t assets rati } \\
\text { hted sample } \\
\text { strain was } \\
\text { tage of hous }\end{array}$ & $\begin{array}{l}\text { in } 2004 \text { with } \\
\text { o" represents } \\
\text { means and re } \\
\text { calculated for } \\
\text { eholds who } \mathrm{n}\end{array}$ & $\begin{array}{l}\text { ent the margi } \\
\text { from not bein }\end{array}$ & $\begin{array}{l}\text { nouseholds v } \\
\text { hal effect for } \\
\text { inancial stra } \\
\text { financially }\end{array}$ & $\begin{array}{l}\text { io" represents } \\
\text { nvestment ass } \\
\text { it change in fi } \\
\text { d measure of } \\
\text { ned in } 2002 \text { to }\end{array}$ & $\begin{array}{l}\text { the percentag } \\
\text { ets/net worth } \\
\text { ancial strain. } \\
\text { ealth status. } \\
\text { being financi }\end{array}$ \\
\hline
\end{tabular}

